\title{
Efeitos do tratamento in vitro do álcool perílico em linhagens de glioblastomas humanos
}

\section{Estudo experimental}

\author{
Clovis Orlando da Fonseca*, Thereza Quírico dos Santos**, \\ Maria da Glória da Costa Carvalho***

\begin{abstract}
Serviço de Neurocirurgia do Hospital Universitário Antônio Pedro. Departamento de Cirurgia Geral e Especializada da Faculdade de Medicina da Universidade Federal Fluminense. Departamento de Biologia Celular e Molecular do Instituto de Biologia da Universidade Federal Fluminense. Instituto de Biofísica Carlos Chagas Filho do Laboratório de Controle da Expressão Gênica da Universidade Federal do Rio de Janeiro
\end{abstract}

\section{RESUMO}

Álcool perílico $(A P)$ é um monoterpeno com efetiva ação quimioterapêutica em tumores pancreáticos, mamários e hepáticos induzidos em animais. O AP induz apoptose e promove diferenciação em células tumorais, sem afetar células normais. O AP vem sendo testado nas fases I e II de ensaios clínicos em pacientes portadores de neoplasias recidivantes.

Analisamos os efeitos do AP em proliferação, alterações morfológicas e síntese de proteínas de linhagens humanas de glioblastomas.

\section{PALAVRAS-CHAVE}

Álcool perílico. Glioblastoma multiforme. Tumor cerebral.

\begin{abstract} glioblastoma cell cultures $\mathrm{POH}$ in patients with advanced and refractory malignancies. and synthesis of proteins, of human cultures glioblastoma cell lines.

KEYWORDS

Perillyl alcohol. Multiforme glioblastoma. Brain tumor.
\end{abstract}

Effects of perillyl alcohol on proliferation, cell morphology and protein synthesis of human

The monoterpene perillyl alcohol $(\mathrm{POH})$ is an effective chemotherapeutic agent for pancreatic, breast and liver cancer induced in animals. $\mathrm{POH}$ is active in inducing apoptosis in tumor cells without affecting normal cells and can revert cells back to a differential state. There are studies in Phase I and Phase II of

The purpose of this study is to evaluate the effects of $\mathrm{POH}$ on proliferation, changes on cell morphology

\section{Introdução}

O glioblastoma multiforme (GBM) é o tumor astrocítico com maior grau de malignidade, sendo composto de astrócitos neoplásicos pobremente diferenciados com áreas de proliferação vascular e/ou necrose. O GBM afeta adultos com maior freqüência e se localiza preferencialmente nos hemisférios cerebrais. De acordo com o sistema St. Anne/Mayo, esses tumores são considerados neoplasias grau IV, devendo preencher três ou quatro critérios histopatológicos, tais como: atipia nuclear, atividade mitótica, proliferação microvascular e/ou necrose ${ }^{21} \mathrm{e}$ correspondem ao grau IV da classificação da Organização Mundial da Saúde ${ }^{17}$. A incidência dos GBM é de $12 \%$ a $15 \%$ entre todas as neoplasias intracranianas e de $50 \%$ a $60 \%$ entre os tumores astrocíticos ${ }^{26}$. Podem desenvolver-se a partir de astrocitoma de baixo grau

\footnotetext{
* Professor Adjunto, Serviço de Neurocirurgia, Hospital Universitário Antônio Pedro, Departamento de Cirurgia Geral e Especializada, Faculdade de Medicina, Centro de Ciências Médicas, Universidade Federal Fluminense, Niterói, RJ, Brasil.

**Professora Titular, Departamento de Biologia Celular e Molecular, Instituto de Biologia, Universidade Federal Fluminense, Niterói, RJ, Brasil.

***Professora Adjunta, Instituto de Biofísica Carlos Chagas Filho, Laboratório de Controle da Expressão Gênica, Universidade Federal do Rio de Janeiro, Centro de Ciências da Saúde.
} 
difuso, ou a partir dos astrocitomas anaplásicos, gerando os chamados glioblastomas secundários; porém, com maior freqüência, manifestam-se após uma história clínica de curta duração, sem evidência de lesão precursora com menor grau de malignidade, constituindo os glioblastomas primários ou glioblastoma "de novo" 21.

Estudos evidenciam que os subtipos de GBM evoluem por meio de transformações genéticas, afetando pacientes em variadas faixas etárias, diferenciando-se provavelmente quanto ao prognóstico e a resposta à terapia instituída ${ }^{28}$. A presença de GBM com alterações genéticas distintas tem sido postulada com base em diferentes combinações de mutações do p53, perda de heterogozidade (LOH) no cromossoma 17 e amplificação do receptor de fator de crescimento epidérmico (EGFR) ${ }^{27}$. A amplificação do EGFR ocorre com maior freqüência em pacientes idosos sem perda de $\mathrm{LOH}$ na região do cromossoma $17 \mathrm{p}^{27}$. Estudos caracterizaram GBM primários como tumores com mutações ausentes do p53, mas com amplificação do EGFR e perda da LOH do cromossoma 10, e GBM secundários como neoplasias com mutações em p53 e $\mathrm{LOH}$ do cromossoma $17^{29}$. Essa assertiva foi endossada em estudos ${ }^{18,28}$ em que autores analisaram as mutações do p53 e a superexpressão do EGFR, em biópsias de GBM primário (“de novo”), com evolução clínica em período inferior a três meses, e GBM secundário, com história clínica de longa duração, e que mostraram evidências nos exames histológicos, da progressão de astrocitoma anaplásico. Eles concluíram após análises das seqüências de DNA que as mutações do p53 eram pouco freqüentes em GBM primários (10\%) e presentes nos GBM secundários (71\%); em contraste, a imunorreatividade para EGFR prevaleceu nos GBMs primários (58\%), mas era rara nos GBMs secundários (6\%). A associação entre a amplificação do EGFR e a deleção do gene CDKN2 também tem sido relatada ${ }^{1}$. Embora as mutações do p53 sejam uma característica de GBM secundários, essa alteração também é encontrada em alguns GBM primários, incluindo GBM de células gigantes ${ }^{21}$. A superexpressão do gene MDM2 é freqüente nos GBM primários (52 \%), mas raro nos GBM secundários (11\%). Nos GBM primários também é comum encontrar deleção de p16. Os GBM de células gigantes, uma variante rara de GBM, são caracterizados pelo aparecimento de células gigantes multinucleadas, tendo como alteração genética característica as mutações freqüentes do p53 e a falta de EGFR superexpresso. Os GBM de tronco cerebral podem se desenvolver "de novo" ou se originar de astrocitomas com menor grau de malignidade. As alterações genéticas normalmente exibidas nesses tumores são: mutações do p53 e a falta de amplificação do $\mathrm{EGFR}^{21}$.

\section{Tratamento neurooncológico dos glioblastomas}

O tratamento dos gliomas malignos do sistema nervoso central (SNC) é efetuado atualmente com ablação cirúrgica, radioterapia e/ou quimioterapia. Porém, os resultados obtidos estão aquém de satisfatórios, com tempo de sobrevida dos pacientes inferior a um ano. Avanços em pesquisa básica têm proporcionado profundos conhecimentos da fisiopatologia de muitas formas de neoplasias e oferecido expectativas para o desenvolvimento de novos medicamentos com atuação específica e seletiva ${ }^{16,18}$. A corrente terapêutica antineoplásica convencional, através de agentes alquilantes, tem como mecanismo de ação atingir macromoléculas vitais como o DNA, ou as vias do metabolismo celular, que são críticas tanto para as células normais como para as células neoplásicas e, como resultado do tratamento, causam muitos efeitos potencialmente tóxicos e indesejáveis. A maioria das drogas antineoplásicas produz efeitos citotóxicos quando atua interferindo nos estágios da síntese, ou quando atua na função vital dos ácidos nucléicos, DNA e RNA. Nos últimos anos, a radioterapia para tumores do sistema nervoso central tem tido uma função considerável, proporcionando o prolongamento da sobrevida, a regressão dos déficits neurológicos e a melhora da qualidade de vida dos pacientes portadores dessas neoplasias. Isso se aplica tanto para as neoplasias malignas primárias como para as metástases e algumas lesões histologicamente benignas ${ }^{22}$. Os gliomas de alto grau geralmente mantêm um prognóstico ruim tanto para pacientes adultos quanto para crianças. Isso sempre é levado em consideração quando doses de radioterapia são recomendadas, porque, quando doses relativamente altas são usadas na tentativa de conseguir a cura ou aumento da sobrevida, sempre existe um alto risco de complicação. Entre as complicações relatadas do tratamento radioterápico para os tumores do SNC, são citadas a radionecrose, as lesões do nervo e do quiasma ópticos, as lesões da medula espinhal, a disfunção hipotálamo-hipofisária e, mais tardiamente, o déficit intelectual ${ }^{21}$.

\section{Efeitos quimioterapêuticos do monoterpeno álcool perílico}

O processo de divisão das células tumorais e das células saudáveis é idêntico; portanto, o melhor caminho para inibir a proliferação de células cancerosas não é destruindo suas propriedades estruturais, mas normalizando o sinal que dirige o seu crescimento 
desordenado, que provém da instabilidade genética, da expressão anormal de genes, da transdução anormal do sinal, da comunicação anormal intercelular e da formação da angiogênese.

Os compostos naturais, produtos derivados da dieta corrente, e que possuem propriedades quimiopreventivas e quimioterapêuticas, têm despertado grande interesse no estudo de pesquisadores, porque são agentes que podem ser encontrados habitualmente, de baixo custo e de baixa toxicidade. Um exemplo desses compostos naturais com propriedades antimitóticas que estão sendo estudados nos últimos anos são os monoterpenos. Terpenos são hidrocarbonetos de origem natural, produzidos a partir de unidades isoprênicas ativadas. Classificam-se quanto ao número de unidades isoprênicas em: monoterpenos (10 átomos de carbono), sesquiterpenos (15 átomos de carbono), triterpenos (30 átomos de carbono) e tetraterpenos (40 átomos de carbono).

O álcool perílico (AP), também chamado p-metha1,7-dieno-6-o1 ou 4-isopropenylciclo-hexenecarbinol, é um monoterpeno encontrado nos óleos essenciais de lavanda, hortelã, salva, cerejas, limão, bergamota selvagem, gengibre e sementes de aipo, que tem ação na inibição seletiva da isoprenilação após tradução da proteína Ras ${ }^{12}$. Estudos em animais têm mostrado que o AP é um poderoso agente quimioterápico, por seus efeitos farmacológicos, na regressão de tumores de mama $^{12}$, pancreáticos ${ }^{25}$, hepáticos ${ }^{20}$, prostáticos ${ }^{15}$, e agente quimiopreventivo para tumores de cólon $^{23}$, melanomas ${ }^{14}$ e neuroblastomas ${ }^{24}$. A atividade antitumoral do álcool perílico pode ser devida, em parte, a sua capacidade em inibir a isoprenilação após tradução de pequenas proteínas $\mathrm{G}$, tal como a Ras, que tem importante papel na transdução do sinal, estando super expressa nos processos neoplásicos e associada ao crescimento celular ${ }^{10,12}$.

O processo de sinalização das vias mitógenas é iniciado quando os oncogenes ativam a junção de um receptor de superfície, como a proteína tirosina cinase (PTK) que, através da liberação de energia, estimula a membrana de junção da proteína Ras. Essa associação impulsiona a cascata de serina-threonina-quinase (Raf), do mitógeno-ativado-quinase (MEK), culminando na intensificação do mitógeno-ativado-proteína-quinase (MAPK), que então se move em direção ao núcleo onde, pela forforilação dos fatores de transcrição, modulam a expressão de uma extensa série de genes envolvidos no crescimento e na sobrevida da célula. As mutações ou as alterações na expressão de cada molécula dessa via levam a uma ativação desordenada, estando diretamente associadas com a iniciação e a progressão do processo neoplásico ${ }^{6}$.

A proteína Ras também funciona como iniciadora de outras reações em cadeia para transdução do sinal, incluindo a ativação das proteínas cinases fosfatidyli- nositol (PI- cinase) e da proteína cinase C (PKC). Uma vez que a proteína Ras está superexpressa em um grande número de neoplasias, exercendo um papel importante nas múltiplas reações em cascata para transdução do sinal, a inibição da ação da Ras é agora considerada uma importante meta na pesquisa para o tratamento do câncer. Além disso, a inibição da ação da Ras é importante porque essa proteína, via estimulação da MAPK, induz a expressão do gene MDM2 cuja proteína atua inibindo a atividade supressora tumoral da proteína p53. Portanto, a atividade da Ras reduz a capacidade da proteína p53 de induzir apoptose nas células cancerígenas. A alteração da transdução do sinal causada pela Ras resulta na alteração da expressão gênica ${ }^{6}$.

Em nossos experimentos prévios, demonstramos que o AP nas concentrações de $30 \%$ a $0,03 \%$ tem ação inibitória na proliferação celular, e em concentrações de $0,3 \%$ e $0,03 \%$ inibe a migração celular em linhagens de glioblastoma murino $\mathrm{C}^{4}$.

\section{Material e métodos}

\section{Cultura de células}

Linhagens de glioblastomas humanos U87 e A172 foram gentilmente fornecidas pelo Dr. Herbert $\mathrm{H}$. Engelhard da University of Illinois at Chicago. As células cresceram como monocamadas em garrafas de $60 \mathrm{~cm}^{2}$ em ambiente de $\mathrm{CO}_{2}$ a $37^{\circ} \mathrm{C}$. O meio de cultura foi o Dulbecco's Modified Eagle Medium (DMEM) com suplemento de 0,2 mM de aminoácidos, penicilina $100 \mathrm{UI} / \mathrm{mL}$, estreptomicina $100 \mathrm{mg} / \mathrm{mL}$ e anfoterecina B $2,5 \mathrm{mg} / \mathrm{mL}$.

\section{Contagem das células}

Células em monocamadas foram trypisinizadas, ressuspensas em meio DMEM e contadas em câmara de Neubauer, e o tratamento foi realizado de acordo com o protocolo abaixo.

\section{Tratamento das células}

Células U87 e A172 foram incubadas por 24 horas em temperatura de $37^{\circ} \mathrm{C}$ com meio DMEM em diferentes concentrações (30\%, 3\%, 0,3\%, 0,03\%, 0,003\% e 0,0003\%) de álcool perílico (Sigma) para o ensaio de MTT. 
Nossos experimentos anteriores demonstraram que o AP nas concentrações de $30 \%$ a $0,3 \%$ possui acentuado efeito inibitório da proliferação celular, em linhagens de glioblastoma humanos, U87 e A172. Para efetuar nossos estudos de morfologia e viabilidade celular e síntese de proteínas fixamos a concentração de $0,3 \%$.

\section{Tratamento de linhagens de glioblastoma U 87 eA 172 para estudo da viabilidade celular pelo azul de tripano}

Para este ensaio, $5 \times 10^{6}$ células foram mantidas em meio DMEM-F12 em garrafa média. A adição do AP deu-se na concentração de $0,3 \%$, tendo sido usado o volume de 15 microlitros. Adicionamos azul de tripano no mesmo volume. Procedemos a análise cinética das alterações das células causadas pelo tratamento, com microfotografias em 100 vezes de aumento. A viabilidade das células não tratadas foi de $100 \%$, enquanto as células tratadas pelo AP mostram intenso sofrimento após 15 minutos e tornam-se inviáveis após 30 minutos.

\section{Tratamento de linhagens de glioma U $87 \mathrm{e}$} A 172 com álcool perílico em concentração de $0,3 \%$, para estudo da morfologia celular

Neste experimento, $5 \times 10^{6}$ células de glioma C6, U87 e A172 foram cultivadas em meio de cultura DMEM-F 12, acrescido de soro fetal bovino a $10 \%$, durante 24 horas de incubação a $37^{\circ} \mathrm{C}$ com $5 \%$ de $\mathrm{CO}_{2}$, em placa de 6 poços. Como controle, foram mantidas células de cada linhagem, em meio de cultura sem tratamento. O tratamento com o AP foi realizado adicionando a droga na concentração de $0,3 \% \mathrm{v} / \mathrm{v}$, em meio de cultura contendo as células a serem estudadas. O período de tratamento foi de 2 horas. Monocamadas das células-alvo, em meio de cultura nos poços-controle, e nos poços contendo células tratadas com AP, foram fotografadas com microscópio óptico invertido NIKON TMS, para registrar as alterações na morfologia celular induzidas pelo tratamento.

\section{Tratamento de linhagens de glioma U 87 e A 172 com álcool perílico em concentração de $0,3 \% \mathrm{v} / \mathrm{v}$, para estudo da morfologia celular em ensaio com azul de tripano}

Após visualizarmos as alterações da morfologia celular com o tratamento do AP a $0,3 \% \mathrm{v} / \mathrm{v}$, procedemos novo experimento com a adição de azul de tripano, para estudarmos sua presença no citoplasma das células.
Neste experimento, $5 \times 10^{6}$ células de glioma C6, U87 e A172 foram cultivadas em meio de cultura DMEM-F 12, acrescido de soro fetal bovino a $10 \%$, durante 24 horas de incubação a $37^{\circ} \mathrm{C} \operatorname{com} 5 \%$ de $\mathrm{CO}_{2}$, em placa de 6 poços. Como controle, foram mantidas células de cada linhagem, em meio de cultura sem tratamento. $\mathrm{O}$ tratamento com o AP foi realizado adicionando a droga na concentração de $0,3 \%$ v/v, em meio de cultura contendo as células a serem estudadas. Após a adição de azul de tripano monocamadas das células-alvo, em meio de cultura nos poços-controle, e nos poços contendo células tratadas com AP, foram fotografadas com microscópio óptico invertido NIKON TMS, em períodos de 15 minutos, 30 minutos, 45 minutos, 1 hora, 2 horas e 3 horas, para registrar as alterações na morfologia celular induzidas pelo tratamento. Todos os experimentos foram feitos três vezes para a garantia de um resultado acurado.

\section{E studo do efeito do A P na inibição da expressão de proteínas, de linhagens de glioblastoma U 87 e A 172}

Após observação dos efeitos do tratamento do AP no crescimento de células de glioblastoma murino C6 e de glioblastoma humanos U87 e A172 pelo método MTT, foi escolhida a concentração de $0,3 \%$ para investigar seu efeito na inibição da síntese de proteínas celulares. Para isso, as células foram previamente tratadas com a droga teste.

Manutenção das células: 5 x $10^{6}$ células de glioblastoma U87 e A172 foram cultivadas em meio de cultura DMEN-F 12 acrescido de soro fetal bovino a $10 \%$, em placas de 24 poços, e em placas de 6 poços em atmosfera de $5 \%$ de $\mathrm{CO}_{2}$ a $37^{\circ} \mathrm{C}$ durante 24 horas.

Tratamento das células: na mesma placa, $5 \times 10^{6}$ células dessas mesmas linhagens foram tratadas com AP em concentração de $0,3 \%$ v/v, sendo utilizados 2 poços para cada linhagem celular submetida ao tratamento com AP. Após 1 hora, o meio de cultura e o meio contendo a droga foram retirados e feito pulso de 500 microlitros de metionona radioativa na concentração de 60 microcurie durante 2 horas. Após esse período, o meio de incorporação com metionina radioativa foi retirado e foram colocados 45 microlitros de tampão de amostra por meio de pipeta em cada poço. Este material foi aquecido a $100^{\circ}$ durante 10 minutos e corridos em gel de proteínas. Posteriormente, as proteínas celulares foram extraídas com tampão de amostra (Tris-HCI pH 6,8, 62,5 mM SDS 2\%; glicerol 10\%; mercaptoetanol 5\%; azul de bromofenol 0,001\%). A preparação de proteínas foi fracionada por eletroforese em gel de poliacrilamida, segundo Laemmli ${ }^{19}$. O gel obtido foi corado com solução de azul de Coomassie 
R-250 e, depois de seco, foi exposto em filme de raio$\mathrm{X}$ Kodak (X-OMAT K), o qual foi revelado para obtenção de auto-radiografia.

\section{Resultados}

Em nossos experimentos, o tratamento in vitro do álcool perílico a $0,3 \% \mathrm{v} / \mathrm{v}$, adicionado ao meio de cultura (DMEM-F12) contendo linhagens de glioblastoma humano U87 e A172, causou alterações da morfologia, como a retração dos prolongamentos das células U87 e A172 e presença de vacúolos no citoplasma. As figuras 1 e 2 mostram essas alterações morfológicas. As figuras 1A e 2A mostram as células U87 e A172 respectivamente, em confluência e não tratadas, e as figuras 1B e 2B mostram as células após 30 minutos de tratamento.

O tratamento in vitro com álcool perílico a $0,3 \% \mathrm{v} / \mathrm{v}$, em experimentos com azul de tripano, evidenciou total inibição da proliferação e da inviabilidade celular, após o período de 30 minutos, em linhagens U87 e A172 (Figura 3).

Os experimentos realizados para determinar se o álcool perílico tem efeito na repressão da expressão de proteínas celulares, mostrou-se positivo para linhagens U87 e A172 (Figura 4).

\section{Discussão}

As formas de tratamento disponíveis até o momento para o astrocitoma maligno, cirurgia, radioterapia e/ou quimioterapia, apresentam eficácia bastante limitada devido à intensa capacidade proliferativa e invasiva do tumor. Embora a amplificação e a sinalização dos receptores tirosina-cinase (Tkr) contribuam para patogênese dos astrocitomas, podem contudo servir como alvo para o desenvolvimento de estratégias de intervenção terapêutica ${ }^{9}$. Estudo recente mostra que tratamento in vitro de gliomas com uma droga inibidora

E feito do tratamento do A P 0,3\% na morfologia e viabilidade de célula U 87. A nálise pelo azul do tripano.

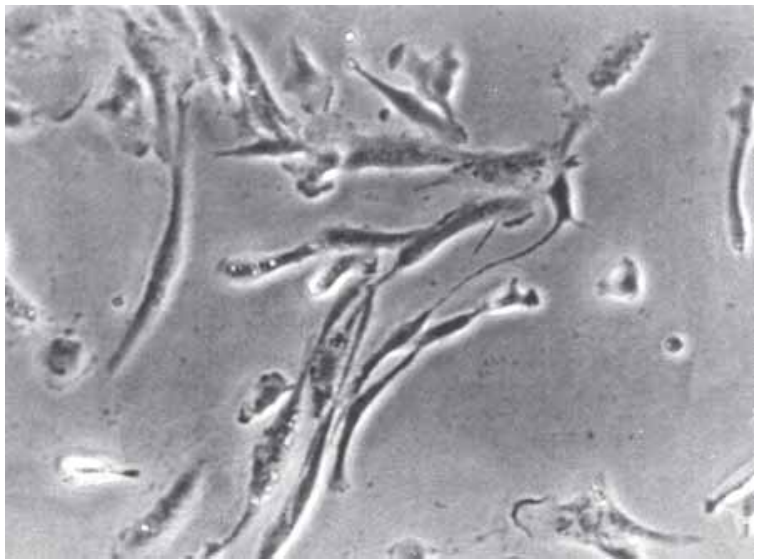

Figura 1A - Célula em confluência.

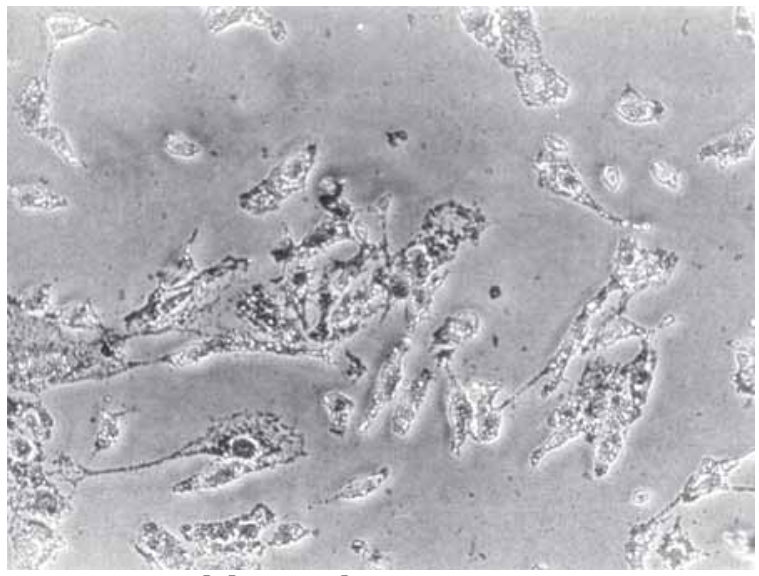

Figura 1B - Células tratadas após 30 minutos.

E feito do tratamento do A P 0,3\% na morfologia e viabilidade de célula A 172. A nálise pelo azul do tripano.

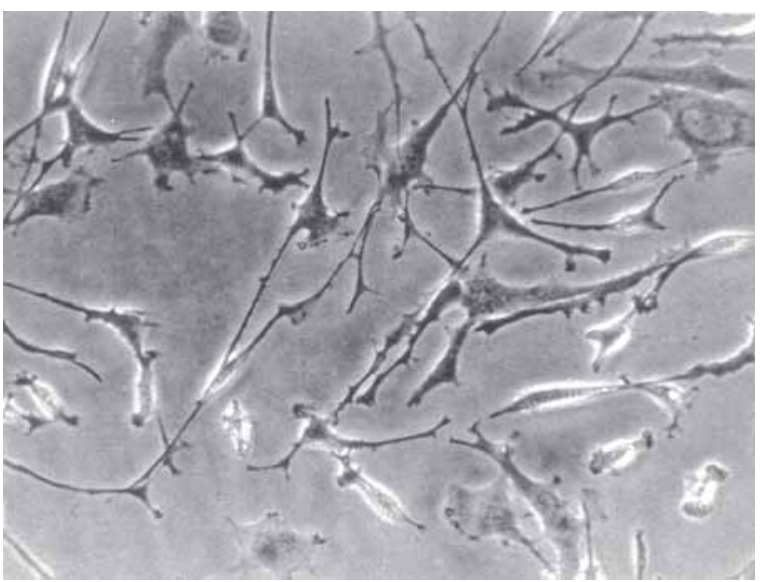

Figura 2A - Célula em confluência.

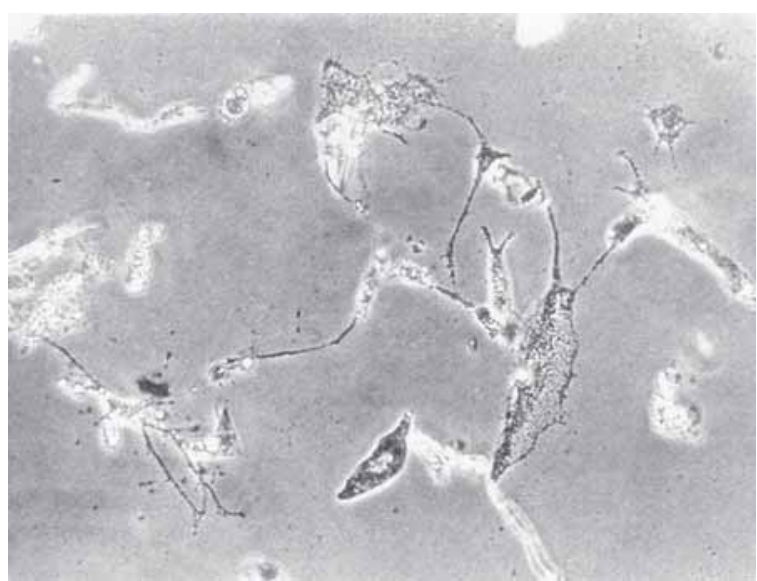

Figura 2B - Células tratadas após 30 minutos. 

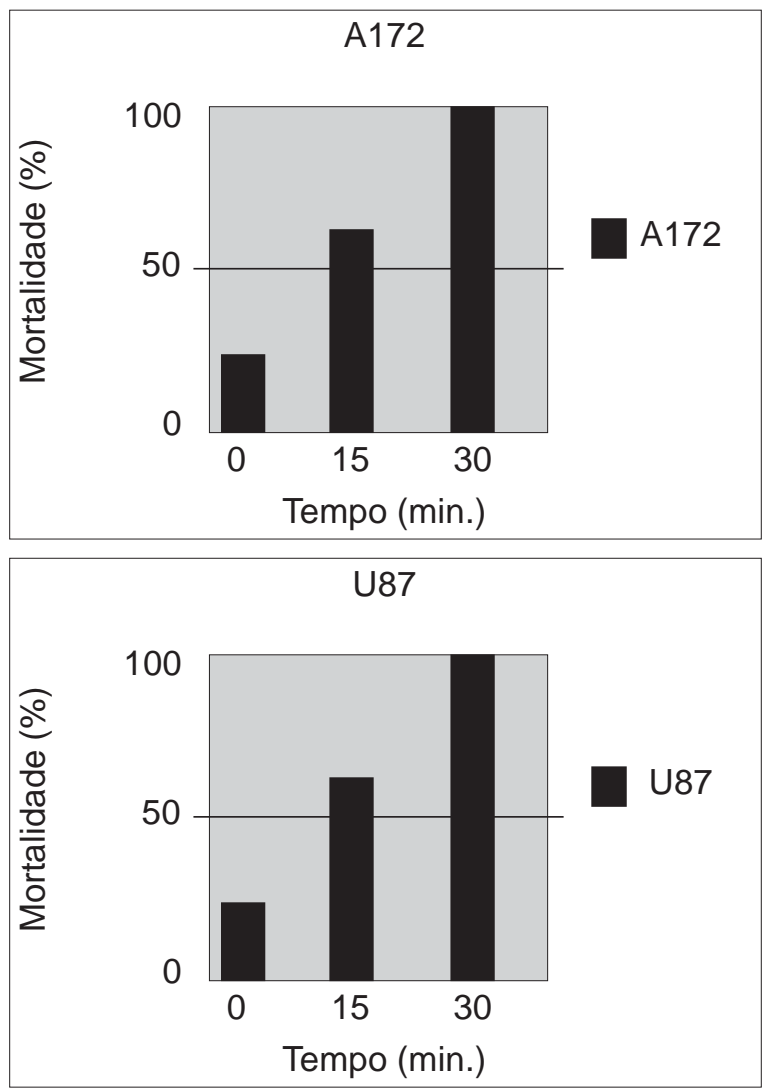

Figura 3 - E feito do tratamento com álcool perílico em células de glioblastoma humano U 87 e A 172, em estudo da viabilidade com azul do tripano.

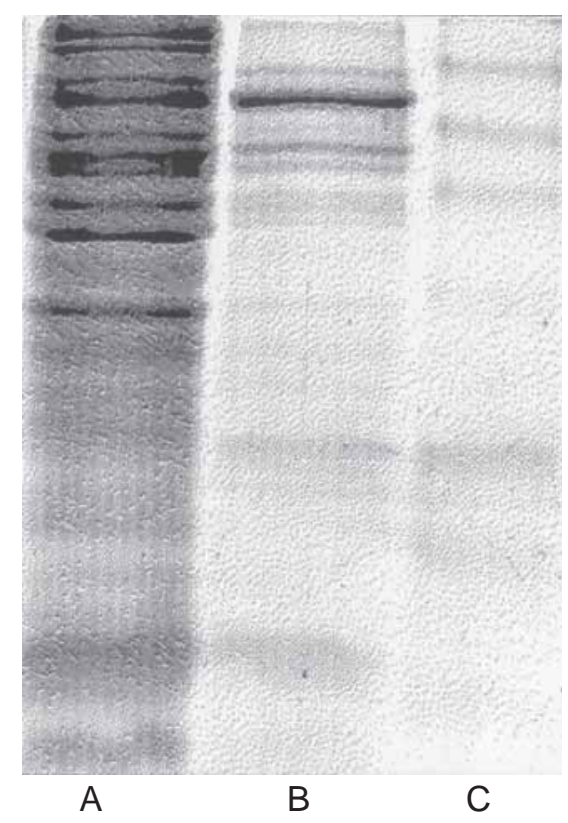

$68 \mathrm{kD}$

$24 \mathrm{kDa}$

Figura 4 - E feito do tratamento do AP na inibição da expressão de proteínas de células A 172.

A - G el de poliacrilamida evidenciando expressão de proteínas em células sem tratamento.

B - G el de poliacrilamida evidenciando inibição da expressão de proténas após 2 horas de tratamento de AP a 0,3\%.

C - Padrão de proteínas. da enzima hidroximetilglutaril-coenzima A-redutase (HMG-CoA-redutase) usada rotineiramente para tratar pacientes com hipercolesterolemia causou apoptose da célula tumoral ${ }^{8}$. O mecanismo provável de ação dessa droga está associado à inibição da isoprenilação de vários membros da superfamília das proteínas Ras determinando a redução da proliferação celular. Ras, uma das famílias de genes que geralmente apresentam mutação pontual nos tumores humanos é constituída por três genes funcionais: H-ras, K-ras e N-ras, que codificam proteínas semelhantes. A semelhança estrutural e funcional das proteínas Ras com as proteínas $G$ que controlam a ativação da enzima adenilciclase indica que as proteínas p21 e Ras participam na transdução do sinal de fatores de crescimento envolvidos na diferenciação celular. Além disso, mutação nos oncogenes Ras causa a perda do controle do processo de ativação celular determinando um crescimento autônomo e desordenado ${ }^{7}$.

Neste estudo demonstramos que o AP tem pronunciado efeito antiproliferativo e diferenciado em linhagens de glioblastoma humano U87 e A172. Também evidenciamos inibição da expressão de proteínas de $18 \mathrm{kDa}$ a $40 \mathrm{kDa}$ nessas linhagens. É importante notar que a proteína oncogênica Ras tem peso molecular de $21 \mathrm{kDa}$, e o efeito terapêutico do AP em células neoplásicas é postulado devido a inibição da isoprenilação após traducão da proteínas Ras e de outras proteínas $\mathrm{G}$, assim como do aumento da proteína pró-apoptóica $\mathrm{Bak}^{10}$. O monoterpeno citotóxico álcool perílico possui propriedades quimiopreventivas e quimioterapêuticas em diversos tipos de neoplasias induzidas em animais, como tumores pancreáticos, mamários e hepáticos ${ }^{5}$, e já vem sendo testados em fases I e II de ensaios clínicos². Nossos experimentos anteriores demonstraram que o AP tem efeito inibitório na proliferação celular e na migração de linhagem de glioblastoma murino C6.

Embora preliminares, os dados apresentados no presente estudo credenciam o álcool perílico a estudos posteriores, visando ao uso dessa substância como possível agente terapêutico para gliomas de alto grau.

\section{Agradecimentos}

Os autores agradecem a Marcelo Soares da Mota e Silva pela excelente assistência técnica, à professora Jane Amaral, pesquisadora do Departamento de Anatomia da Universidade Federal do Rio de Janeiro, pela valiosa contribuição e orientação para realização dos experimentos, à Faperj, CNPq e FUJB pelo suporte financeiro. 


\section{Referências}

1. ARAP W, NISHIKAWA R, FURNARI FB, CAVENEE WK, HUANG HJ: Replacement of the p16/CDKN2 gene suppresses human glioma cell growth. Cancer Res 55:1351-4, 1995.

2. BAILEY HH, LEVY D, HARRIS LS, SCIHNK JC, FOSS F, WADLERS: A phase II trial of dally perillyl alcohol in patients with advanced ovarian cancer. Gynecol Oncol 85:464-8, 2002.

3. BAILEY P, CUSHING $\mathrm{H}$ : A classification of tumors of the glioma group on a histogenetic basis with a correlation study of prognosis. Philladelphia, Lippincott, 1926.

4. BALASSIANO IT, De PAULO S, SILVANH, CABRAL MC, GIBALDI D, BOZZA M et al.: Effects of prillyl alcohol in glial cell line in vitro and anti-metastatic activity in chorioallantoic membrane model. Internat J Molec Med 10:785-8, 2002.

5. BELANGER JT: Perillyl alcohol: applications in oncology. Altern Med Rev 3:448-57, 1998.

6. BOIK J: Natural compounds in cancer therapy. 1st ed. Princeton, Minessota, Oregon Medical Press, 2001.

7. BOS JL: Ras oncogenes in human cancer: a review. Cancer Res 49:4682-9, 1989.

8. BOUTERFA HL, SATTELMEYER V, CZUB $S$, VORDERMARK D, ROOSEN K, TONN JC: Inhibition of Ras farnesylation by lovastatin leads to downregulation of proliferation and migration in primary cultured human glioblastoma cells. Anticancer Res 20:2761-71, 2000.

9. CIORDIA R, SUPKO J, GATINEAU M, BATCHELOR T: Cytotoxic chemotherapy: advances in delivery, pharmacology, and testing. 1: Curr Oncol Rep 2:445$53,2000$.

10. CROWELL PL, RES R, LIN S, VEDEJS E, GOULD MN: Structure-activity relationships among monoterpene inhibitors of protein isoprenylation and cell proliferation. Biochem. Pharmacol 47:1404-15, 1994.

11. DAUMAS DUPORT C, SCHEITHUER B, O'FALLON J, KELLY P: Grading of astrocytomas. A simple and reproducible method. Cancer 62:2152-65, 1988.

12. HAAG JD, GOULD MN: Mammary carcinoma regression induce by perillyl alcool, a hidroxylated analog of limonene. Cancer Chemother Pharmacol 34:477-83, 1994.

13. HAAG JD, LINDSTROM MJ, GOULD MN: Limonenoinduced regression of mammary carcinomas. Cancer Res 52:4021-6, 1992.

14. HE L, MO H, HADISUSILO S: Isoprenoids supress the growth of murine B16 melanomas in vitro and in vivo. J Nutr 127:668-74, 1997.

15. JEFFERS L: The effect of Perillyl Alcohol on the proliferation of human prostatic cell lines. Proc Am Assoc Cancer Res 36:303-7, 1995.

16. KIRSCH M, ZHU J, CEVENEE W: Pathogenetic mechanisms of nervous system tumors In Black $\mathrm{P}, \mathrm{Mc}$ Loeffler J (eds): Cancer of the Nervous System. Cambridge, MA, Blackwell Sciences, pp 703-73, 1997.

17. KLEIHUES P, LOUIS DN, SCHEITHAUER BW, BURGER DC, CAVENEE WK. The WHO classification of tumor of the nervous system. International Agency for Research on Cancer. J Neuropathol Exp Neurol 61: 215-25, 2002.
18. KOHN KW, JACKMAN JO', CONNOR PM: Cell cycle control and cancer chemotherapy. J Cell Biochem 54:440-52, 1994.

19. LAEMMLI UK: Cleavage of structural proteins during the assembly of the head of bacteriophage T4. Nature 227 : 680-5, 1970

20. MILLS JJ, CHARI RS, BOYER IJ, GOULD MN, JIRTLE RK: Induction of apoptosis in liver tumors by the monoterpene parillyl alcohol. Cancer Res 55:97983,1995.

21. PAUL KLEIHUES, WESSTER KC: Pathology and Genetics. Tumours of the Nervous System. Lyon, International Agency for Research on Câncer, 1998.

22. PEREZ CA, BRADY LW: Principles and Practice of Radiation Oncology. Philadelphia, Lippincott, 1987.

23. REDDY BS, WANG CX, SAMAHA H et al: Chemoprevention of colon carcinogenesis by dietary perillyl alcohol. Cancer Res 57:420-5, 1997.

24. SHIW H, GOULD MN: Induction of differentiation in Neuro-2A Cells by the monoterpene Perillyl Alcohol. Cancer Lett 95:1-6, 1997.

25. STARK MJ, BURKE YD, MAKINZIE JH, AYUOBI AS, CROWELL PL: Chemotherapy of pancreatic cancer with the monoterpene perillyl alcohol. Cancer Lett 9:15-21, 1995.

26. Von DOIMLING A, LOUIS DV, WIESTLER. D: Molecular pathways in the formation of gliomas. Glia 15:328-38, 1995.

27. WATANABE K, TACHIBANA O, SATO K, YONEKAWA $Y$, OHGAKI H, KLEIHUES P: Overexpresion of the EGF receptor and $\mathrm{P} 53$ mutation are mutually exclusive in the evolution of primary and secundary glioblastomas. Brain Pathol 6:217-24, 1996.

28. WATANABI K, BIERNAT W, PERAUD A, TACHIBANA O, SATO K, KLEIHUES P et al. Genetics of glioma progression and the definition of primary and secundary glioblastoma.

29. WATANABE K, BIIERNAT W, TACHIBANA O, SATO K, KLEIHUES $P$, OHGAKI $\mathrm{H}$, in colaborations with FEARON ER (USA), PLATE K (Germany), REYES- MUGICA M and REALE M (USA) and YONEKAWA Y (Switzerland): International Agency for Research on Cancer. Biennial Report, 1996-1997.

Original recebido em fevereiro de 2003

Aceito para publicação em junho de 2003

\section{E ndereço para correspondência:}

Clovis Orlando da Fonseca

Instituto de Biofísica Carlos Chagas Filho do Laboratório de Controle da Expressão Gênica da Universidade Federal do Rio de Janeiro, Centro de Ciências da Saúde, Bloco G,

Cidade Universitária

CEP 21949-900 - Rio de Janeiro, $R J$

E-mail: clovisorlando@wnetrj.com.br 